\title{
A comparison of the effects of dexamethasone-pharmacopuncture and dexamethasone-oral administration based on traditional Korean medicine theory on anaphylactic reaction in mice
}

Jaehak Kim, Doyoung Kang, Minsu Kang, Bora Kang, Eun Byeol Kang, Jinseok Kang, YaeJin Go, Wheehyoung Ko, JaeYoung Kwak, Hyunjung Ku, Seo Yeon Gwon, Yumi Gi, Gayeon Kim, GyeongMuk Kim, Kyunghoon Kim, Kyuri Kim, Dong hyun Kim, MinWoo Kim, Min Chae Kim, Seongho Kim, Seyoon Kim, Shilla Kim, ShinHyung Kim, Young-jun Kim, JongHyeon Kim, Jisu Kim, Sunwoo Nam, Taeyun Doh, HaYoon Do, Gi-yeok Moon, GyeongRok Min, Kyoung-Keun Park, Minyoung Park, Sungmin Park, InWoo Park, Jun-Gyu Park, Junhan Park, Jung-Gun Park, Jieun Park, Taeki Park, Junhyeong Bae, JungWuck Byun, Se Wook Seo, Hyejin Seo, Kangmin Son, Chang Gyu Song, Hyejin Shin, Hee-yeon Shin, Eun-Kyu Sim, Sangkyu An, JeongEun Ahn, Jung Yun Yang, Daeyoon Ok, Gunhee Yoon, Sung Soo Yoon, Yeji Yoon, JinYoung Yoon, Kang eun Lee, KyoungChae Lee, DongWoo Lee, Myeong Hun Lee, SangWon Lee, SangHwa Lee, Sung Ho Lee, So Yeon Lee, Soobok Lee, Yena Lee, Jungju Lee, Joon Seung Lee, JiYoung Lee, JiHan Lee, JinWook Lee, Chang Hee Lee, Chang Hee Lee, Sol Lim, Sujeong Lim, Hyung Geun Rheem, Hyunjung Jun, Beomseog Jeong, InHwa Chung, Jemin Jung, SeongHwan Cho, Wonpil Cho, Eunbyul Cho, SeongHee Joo, HaeRi Ji, Seongtaek Cheon, Inseok Choi, Jaehee Choi, Ji Hye Choi, Nakyung Han, SeungHo Han, Eugene Huh, Ye-Jin Hong, Jihyun Hong, Mini Hwang, Phil-Dong Moon*

Department of Pharmacology, College of Korean Medicine, Kyung Hee University, Dongdaemun-Gu, Seoul 130-701, Republic of Korea

\begin{abstract}
Pharmacopuncture, or herbal acupuncture, is a new form of therapy derived from combinations of two traditional therapeutic methods, herbal medicine and acupuncture therapy. To compare the efficacy between dexamethasone-pharmacopuncture (DP) and dexamethasone-oral administration (DO), the effect of DP was investigated in murine models. Anti-anaphylactic effects of dexamethasone treatments were investigated in compound 48/80-induced systemic anaphylactic reaction, ear swelling response, and passive cutaneous anaphylaxis (PCA). DP treatment significantly inhibited the compound 48/80-induced systemic anaphylactic reaction, ear swelling response, and PCA. The effects between DP and DO were on a similar level. These results indicate that DP can be used as an alternative method for DO in case of emergency.
\end{abstract}

Keywords dexamethasone-pharmacopuncture, systemic anaphylactic reaction, ear swelling response, passive cutaneous anaphylaxis

\section{INTRODUCTION}

Pharmacopuncture, or herbal acupuncture, is a new form of therapy derived from combinations of two traditional therapeutic methods, herbal medicine and acupuncture therapy. Pharmacopuncture is mainly categorized depending on the medicinal materials used. There are four main categories: meridian-field pharmacopuncture, eight-principle pharmaco puncture, bee-venom pharmacopuncture, and single-compound pharmacopuncture. Among them, single-compound pharmacopuncture uses extracts from medicinal materials such as Hominus placenta, Scolopendrid, wild ginseng and ginger (Kim and Kang, 2010). Single-compound pharmacopuncture traditionally has used eastern medicinal materials; however, we used western medicinal material in this study. We used the

\footnotetext{
*Correspondence: Phil-Dong Moon

E-mail: pdmoon@khu.ac.kr

Received July 4, 2013; Accepted August 21, 2013; Published

August 31, 2013

doi: http://dx.doi.org/10.5667/tang.2013.0017

C2013 by Association of Humanitas Medicine
}

principle of pharmacopuncture treatment, but selected a material from western medicinal materials that work fast. Glucocorticoids are a class of steroid hormones that bind to intracellular glucocorticoid receptors (GRs). In turn, the GR complex migrates to the nucleus where it inhibits nuclear factor $(\mathrm{NF})-\kappa \mathrm{B}$ and activator protein (AP)-1 driven gene expression (Barnes, 2006). Moreover, glucocorticoids may suppress granulocyte activation and recruitment, preserve endothelial cell integrity and control vascular permeability (Thompson, 2003). Dexamethasone (Dex) is a synthetic glucocorticoid which shows a 20 to 30 times higher potency to evoke antiinflammatory effects relative to the endogenously produced cortisol (Blaser et al., 2011). It has been reported that the glucocorticoid Dex has an antiallergic activity and clinical efficacy in allergic diseases (Puigneró et al., 1995; Wershil et al., 1995). Thus, here we compared the efficacy between dexamethasone-pharmacopuncture (DP) and dexamethasoneoral administration (DO) in mice.

ST36 is a specific acupoint located on the stomach meridian (足陽明胃經) and known to strengthen the Qi, not only the stomach Qi, even though this acupoint belongs to the 
stomach meridian but also the general Qi in the whole body. ST36 is one of the most frequently used acupoints that can be stimulated through needles or "moxibustion" to balance and harmonize Yin and Yang by improving the flow of Qi along the meridians. For this reason, ST36 is the target to treat various diseases in the gastrointestinal tract as well as general symptoms in the whole body (Hu et al., 2013).

Mast cells are regarded as critical effector cells in the allergic and inflammatory reactions that underlie immediatetype hypersensitivity reaction-mediated clinical conditions such as urticaria, allergic rhinitis, bronchial asthma, and atopic dermatitis (Emi and Maeyama, 2004; Miescher and Vogel, 2002). The release of vasoactive substances is produced locally in naive animals using the $\operatorname{IgE}$ of animals. $\mathrm{IgE}$ is injected intradermally into naive animals and the tested substance mixed with a dye (typically Evan's blue) is subsequently administered intravenously (usually after $24-72$ h). Subsequent to the antigen-antibody reaction, vasoactive substances are released, resulting in a dramatic local increase in vascular permeability (Bazin et al., 1990). As the tested substance is mixed with a dye, the local cutaneous reaction is evidenced by a colored spot (Verdier et al., 1994). Activated mast cells can produce histamine as well as a wide variety of other inflammatory mediators as well as several proinflammatory and chemotactic cytokines, such as tumor necrosis factor (TNF)- $\alpha$, interleukin (IL)-6, IL-8, and IL-13 (Royer et al., 2001; Stassen et al., 2001). Histamine is a well characterized and potent vasoactive mediator that has been implicated in the acute phase of immediate-type hypersensitivity reactions among the substances released upon the degranulation of mast cells (Moon et al., 2004; 2005; Petersen et al., 1996).

Mouse models were used to compare the efficacy between DP and DO in the anaphylactic shock, ear swelling response and passive cutaneous anaphylaxis (PCA).

\section{MATERIALS AND METHODS}

\section{Materials}

Compound 48/80, anti-dinitrophenyl (DNP) IgE antibody, DNP-human serum albumin (HSA), Dex, and Evans blue were purchased from Sigma Chemical Co. (St. Louis, MO, USA).

\section{Animals}

The original stock of male ICR mice (5 weeks old) were purchased from the Dae-Han Experimental Animal Center (Eumsung, Chungbuk, Republic of Korea), and the animals were maintained at the College of Korean Medicine, Kyung Hee University. Five to seven animals were housed per cage in a laminar air-flow room maintained at a temperature of $22 \pm$ $1{ }^{\circ} \mathrm{C}$ and relative humidity of $55 \pm 1 \%$ throughout the study. No animal was used more than once. The research was conducted in accordance with the internationally accepted principles for laboratory animal use and care as found in the US guidelines (NIH publication \#85-23, revised in 1985).

\section{Dex treatment}

Mice were divided randomly into 'DP', 'DO' and 'Control' groups. The concentration of Dex injected each mouse of DP group was 10 times higher than DO group, but 10 times less in volume. The Zusanli acupoint (ST36) is located $5 \mathrm{~mm}$ below and lateral to the anterior tubercle of the tibia. Dex $(3 \mathrm{mg} / \mathrm{kg})$ was injected into ST36 acupoint of each mouse (DP group) using a microsyringe with a 29-gauge hypodermic needle and administered orally with sonde in DO group.

\section{Compound 48/80-induced systemic anaphylactic reaction}

Mice $(n=4)$ were given an intraperitoneal injection of the mast cell degranulator compound 48/80 (8 mg/kg). Dex was dissolved in saline and treated $1 \mathrm{~h}$ before the injection of compound 48/80. The period for observation of mortality was based on the control mice that had died in 18 min by compound 48/80. Mortality was monitored for $18 \mathrm{~min}$ after induction of anaphylactic reaction.

\section{Ear swelling response}

Compound 48/80 was freshly dissolved in saline and injected intradermally into the dorsal aspect of a mouse $(n=4)$ ear using a microsyringe with a 29 -gauge hypodermic needle. Ear thickness was measured with a digimatic micrometer (Mitutoyo, Japan) under mild anesthesia. Ear swelling response represented an increment in thickness above baseline control values. Ear swelling response was determined $40 \mathrm{~min}$ after compound $48 / 80$ or vehicle injection. Dex treatment of each group was performed $1 \mathrm{~h}$ before the compound 48/80-injection $(100 \mu \mathrm{g} / \mathrm{site})$. The values obtained appear to represent the effect of compound 48/80 rather than the effect of the vehicle injection (physical swelling), as the ear swelling response evoked by physiologic saline returned to nearly the baseline thickness within $40 \mathrm{~min}$. The inhibition rate of the ear swelling response was calculated using the following equation:

$\%$ inhibition $=(\mathrm{A}-\mathrm{B}) \times 100 / \mathrm{A}$

in which $\mathrm{A}$ is the ear thickness (mm) without Dex treatment and $B$ is the ear thickness (mm) with Dex treatment.

\section{PCA reaction}

The mice $(n=4)$ were injected intradermally with $100 \mathrm{ng}$ of anti-DNP IgE antibody into left dorsal skin site that had been shaved and equal volume of phosphate-buffered saline (PBS) into right dorsal skin. The sites were outlined with a waterinsoluble red marker. Forty-eight hours later, each mouse received an injection of $200 \mu \mathrm{l}$ of a 1:1 mixture of $1 \mathrm{mg} / \mathrm{ml}$ DNP-HSA in PBS and 4\% Evans blue via the tail vein. Dex treatment of each group was performed $1 \mathrm{~h}$ before this injection. The mice were sacrificed $40 \mathrm{~min}$ after the intravenous challenge. The dorsal skin of the mouse was removed for the measurement of the pigment area. The amount of dye was then determined colorimetrically after extraction with $0.5 \mathrm{ml}$ of $1 \mathrm{~N}$ $\mathrm{KOH}$ and $4.5 \mathrm{ml}$ of a mixture of acetone and phosphoric acid (with a ratio of 13:5) based on the method of Katayama et al. (1978). The absorbent intensity of the extraction was measured at $620 \mathrm{~nm}$ in a spectrofluorometer, and the amount of dye was calculated with the Evans blue measuring-line. The inhibition rate of PCA was calculated using the following equation:

$\%$ inhibition $=(\mathrm{A}-\mathrm{B}) \times 100 / \mathrm{A}$

in which $\mathrm{A}$ is the amount of dye without Dex treatment and B is the amount of dye with Dex treatment.

\section{Statistical analysis}

The results are expressed as the mean \pm standard error of the mean (S.E.M.). The statistical evaluation of the results was performed by an independent t-test. The results are significant with a value of $p<0.05$.

\section{RESULTS}

Comparison of the effects between DP and DO on compound 48/80-induced systemic anaphylaxis To compare the contribution between DP and DO in anaphylactic reaction, we first used the in vivo model of 
Table 1. Effect of DP or DO on compound 48/80-induced systemic anaphylactic reaction in mice

\begin{tabular}{lcc}
\hline \multicolumn{1}{c}{ Treatment } & $\begin{array}{c}\text { Compound 48/80 } \\
(\mathbf{8 ~} \mathbf{~ m g} / \mathbf{k g})^{\mathbf{b}}\end{array}$ & Mortality (\%) $^{\mathbf{c}}$ \\
\hline None $($ saline $)$ & + & $100.00 \pm 0.00$ \\
DP $(3 \mathrm{mg} / \mathrm{kg})$ & + & $12.50 \pm 6.25^{*}$ \\
DO $(3 \mathrm{mg} / \mathrm{kg})$ & + & $12.50 \pm 6.25^{*}$ \\
${ }^{\text {a }}$ The groups of mice $(\mathrm{n}=4 /$ group) & were pretreated with Dex $1 \mathrm{~h}$ \\
before the compound $48 / 80$ injection. ${ }^{\mathrm{b}}$ The compound $48 / 80$ solution \\
was intraperitoneally given to the groups of mice. ${ }^{\mathrm{c}}$ Mortality $(\%)$ is \\
presented as the 'number of dead mice $\times 100 /$ Total number of \\
experimental mice'. Each datum represents the mean \pm S.E.M. of \\
three independent experiments. ${ }^{*} p<0.05$; significantly different from \\
the control value
\end{tabular}

systemic anaphylaxis. As shown in Table 1, an oral administration of saline as a control induced $100 \%$ of fatal reaction. When the Dex was treated to the mouse $1 \mathrm{~h}$ before compound $48 / 80$ injection, the mortality was significantly reduced at both groups (Table 1 ).

Comparison of the effects between DP and DO on ear swelling response

That an intradermal application of compound 48/80 at a concentration of $50-200 \mu \mathrm{g} / \mathrm{site}$ can induce an ear swelling response in normal mice was confirmed in a previous experiment (Shin et al., 2004). In the present study, a concentration of $100 \mu \mathrm{g} / \mathrm{site}$ was chosen for the compound 48/80-induced optimal ear swelling response. As shown in Table 2, the ear swelling response derived from compound 48/80 was inhibited in both groups; however, DP was better than DO.

\section{Comparison of the effects between DP and DO on PCA}

PCA is one of the most important in vivo models of anaphylaxis in local allergic reactions (Wershil et al., 1987). When the Dex was treated to the mouse, the PCA reaction was inhibited (Fig. 1). The best result was obtained at DP group. Amounts of increased dye at DP and DO groups were $0.15 \pm$ 0.03 and $0.19 \pm 0.06$, respectively. The amount of increased dye in control mice was $0.58 \pm 0.04$.

\section{DISCUSSION}

The present study showed that DP treatment inhibited the systemic anaphylactic reaction, ear swelling responses, and PCA in mice. Even the inhibitory effects of DP were better than those of DO.

Stimulation of mast cells with compound $48 / 80$ is believed

Table 2. Effect of DP or DO on compound 48/80-induced ear swelling response in mice

\begin{tabular}{lccc}
\hline Treatment & $\begin{array}{c}\text { Pre-thickness } \\
(\mathbf{m m})\end{array}$ & $\begin{array}{c}\text { Post-thickness } \\
(\mathbf{m m})\end{array}$ & $\begin{array}{c}\text { Inhibition } \\
(\boldsymbol{\%})\end{array}$ \\
\hline None (saline) & $0.31 \pm 0.03$ & $0.74 \pm 0.04$ & $0.00 \pm 2.09$ \\
& & & \\
$\mathrm{DP}(3 \mathrm{mg} / \mathrm{kg})$ & $0.30 \pm 0.04$ & $0.60 \pm 0.06$ & $30.23 \pm 4.90^{*}$ \\
& & & \\
$\mathrm{DO}(3 \mathrm{mg} / \mathrm{kg})$ & $0.31 \pm 0.02$ & $0.62 \pm 0.05$ & $27.91 \pm 3.32^{*}$
\end{tabular}

The groups of mice ( $n=4$ /group) were pretreated with Dex $1 \mathrm{~h}$ before the compound 48/80 injection. Twenty microliters of compound 48/80 $(100 \mu \mathrm{g} / \mathrm{site})$ were injected intradermally. Results represent the mean \pm S.E.M. of threeindependent experiments. ${ }^{*} p<0.05$; significantly different from the control value.

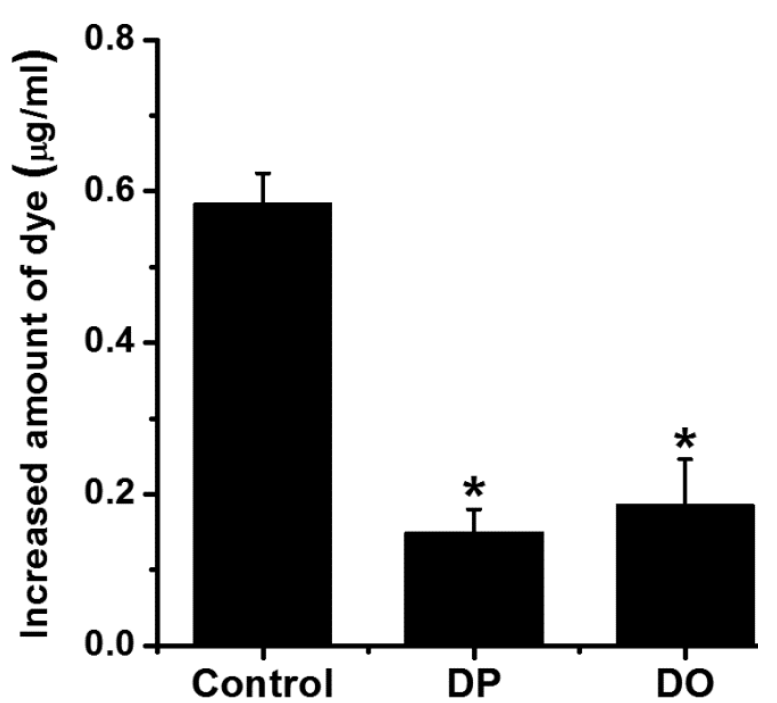

Fig. 1. Effect of DP or DO on $48 \mathrm{~h}$ PCA in mice. The groups of mice (n $=4$ /group) were pretreated with Dex $1 \mathrm{~h}$ before antigen (DNP-HSA) injection. Each datum represents the mean \pm S.E.M. of three independent experiments. ${ }^{*} p<0.05$; significantly different from the control value.

to initiate the activation of a signal transduction pathway, which leads to a histamine release. There have been some reports that compound $48 / 80$ is able to activate $\mathrm{G}$ proteins (Mousli et al., 1990a, b). Chadi et al. (2000) announced that compound 48/80 activates mast cell phospholipase D (PLD) via heterotrimeric GTP-binding proteins. They identified recombinant $\mathrm{G} \beta_{2} \gamma_{2}$ subunit markedly synergized PLD activation by compound $48 / 80$ in permeabilized RBL-2H3 cells Murine mast cells are a good experimental model for the study of compound 48/80-induced histamine release (Alfonso et al., 2000). A report that compound $48 / 80$ increased the permeability of the lipid bilayer membrane by causing a perturbation of the membrane (Tasaka et al., 1986) indicates that this membrane permeability increase may be an essential trigger for the release of mediators from mast cells. Our results showed that the DP treatment inhibited the compound 48/80induced systemic anaphylactic reaction and ear swelling response (Tables 1 and 2). Thus, it is possible to hypothesize that the DP treatment may not act on the lipid bilayer membrane affecting the prevention of the perturbation induced by compound $48 / 80$.

The high-affinity IgE-receptor (FceRI) is expressed primarily by mast cells (Daeron, 1997). Cross-linking of IgEbound FceRIs by a multivalent $\mathrm{Ag}$ on mast cells induces the release of biologically active mediators: the preformed mediators stored in the cytoplasmic granules, including histamine and $\beta$-hexosaminidase, and the newly synthesized mediators, such as leukotrienes and cytokines (Galli et al., $2005 \mathrm{a}, \mathrm{b}$ ). To reproduce these reactions in animals, a PCA model was used in passively sensitized mice. Our results showed that the DP treatment inhibited PCA (Fig. 1). It is conceivable that the DP treatment inhibits the immediate type allergic reactions, probably through interference with the degranulation system.

Overall, the present findings suggest that the DP treatment has a potential as a new method to administer a drug to human who are difficult to take a drug orally.

\section{ACKNOWLEDGEMENTS}

This work was supported by Kyung Hee University. 


\section{CONFLICT OF INTEREST}

The authors declare that there was no conflict of interest.

\section{REFERENCES}

Alfonso A, Cabado AG, Vieytes MR, Botana LM. Functional compartments in rat mast cells for cAMP and calcium on histamine release. Cell Signal. 2000;12:343-350.

Barnes PJ. How corticosteroids control inflammation. Quintiles Prize Lecture 2005. Br J Pharmacol. 2006;148:245-254

Bazin H, Barta O, Barta VD. Hypersensibility de type I. In Immunologie Animale. Pastoret P, Govaerts A, Bazin H eds. (Paris, France: Flammarion), p. 313, 1990.

Blaser C, Wittwer M, Grandgirard D, Leib SL. Adjunctive dexamethasone affects the expression of genes related to inflammation, neurogenesis and apoptosis in infant rat pneumococcal meningitis. PLoS One. 2011;6:e17840.

Chadi A, Fraundorfer PF, Beaven MA. Compound 48/80 activates mast cell phospholipase D via heterotrimeric GTPbinding proteins. J Pharmacol Exp Ther. 2000;292:122-130.

Daeron M: Fc receptor biology. Annu Rev Immunol 1997;15:203-234.

Emi M, Maeyama K. The biphasic effects of cyclopentenone prostaglandins, prostaglandin $\mathrm{J}(2)$ and 15-deoxy-Delta(12,14)prostaglandin $\mathbf{J}(2)$ on proliferation and apoptosis in rat basophilic leukemia (RBL-2H3) cells. Biochem Pharmacol. 2004;67:1259-1267.

Galli SJ, Kalesnikoff J, Grimbaldeston MA, Piliponsky AM, Williams CM, Tsai M. Mast cells as "tunable" effector and immunoregulatory cells: recent advances. Annu Rev Immunol. 2005a;23:749-786.

Galli SJ, Nakae S, Tsai M: Mast cells in the development of adaptive immune responses. Nat Immunol. 2005b;6:135-142.

Hu S, Du MH, Luo HM, Wang H, Lv Y, Ma L, Lin ZL, Shi X, Gaischek I, Wang L, Litscher G. Electroacupuncture at Zusanli (ST36) Prevents Intestinal Barrier and Remote Organ Dysfunction following Gut Ischemia through Activating the Cholinergic Anti-Inflammatory-Dependent Mechanism. Evid Based Complement Alternat Med. 2013;2013:592127.

Katayama S, Shionoya H, Ohtake S. A new method for extraction of extravasated dye in the skin and the influence of fasting stress on passive cutaneous allergy in guinea pigs and rats. Microbiol Immunol. 1978;22:89-101.

Kim J, Kang DI. A descriptive statistical approach to the Korean pharmacopuncture therapy. J Acupunct Meridian Stud. 2010;3:141-149.

Miescher SM, Vogel M. Molecular aspects of allergy. Mol Aspects Med. 2002;23:413-462.

Moon PD, Choi IY, Na HJ, Jeong HJ, Kim CH, Kim HR, Kim
YK, Park SK, Hong SH, Kim HM. Rubus croceacanthus Leveille inhibits mast cell-mediated anaphylactic-like reaction and tumor necrosis factor- $\alpha$ secretion. Biol Pharm Bull. 2004;27:1359-1363.

Moon PD, Na HJ, Jeong HJ, Hong SH, Kim SJ, Chae HJ, Kim HR, Choi JO, Lee SH, Shin JY, Kim HM. Inhibitory effect of Gamibojungikgitang extract on mast cell-mediated allergic reaction in murine model. J Pharm Pharm Sci. 2005;8:94-101.

Mousli MC, Bronner C, Bockaert J, Rouot B, Landry Y. Interaction of substance $\mathrm{P}$, compound $48 / 80$ and mastoparan with $\alpha$-subunit $\mathrm{C}$-terminal of $\mathrm{G}$ protein. Immunol Lett. 1990a;25:355-358.

Mousli MC, Bronner C, Landry Y, Bockaert J, Rouot B. Direct activation of GTP-binding regulatory proteins ( $\mathrm{G}$ proteins) by substance P and compound 48/80. FEBS Lett. 1990b;25:260262

Petersen LJ, Mosbech H, Skov PS. Allergen-induced histamine release in intact human skin in vivo assessed by skin microdialysis technique: characterization of factors influencing histamine releasability. J Allergy Clin Immunol. 1996;97:672679.

Puigneró V, Salgado J, Queralt J. Effects of cyclosporine and dexamethasone on IgE antibody response in mice, and on passive cutaneous anaphylaxis in the rat. Int Arch Allergy Immunol. 1995;108:142-147.

Royer B, Varadaradjalou S, Saas P, Gabiot AC, Kantelip B, Feger F, Guillosson JJ, Kantelip JP, Arock M. Autocrine regulation of cord blood-derived human mast cell activation by IL-10. J Allergy Clin Immunol. 2001;108:80-86.

Shin HY, Na HJ, Moon PD, Shin T, Shin TY, Kim SH, Hong $\mathrm{SH}$, Kim HM. Inhibition of mast cell-dependent immediatetype hypersensitivity reactions by purple bamboo salt. J Ethnopharmacol. 2004;91:153-157.

Stassen M, Muller C, Arnold M, Hultner L, Klein-Hessling S, Neudorfl C, Reineke T, Serfling E, Schmitt E. IL-9 and IL-13 production by activated mast cells is strongly enhanced in the presence of lipopolysaccharide: NF-kappa B is decisively involved in the expression of IL-9. J Immunol. 2001;166:43914398

Tasaka K, Mio M, Okamoto M. Intracellular calcium release induced by histamine releasers and its inhibition by some antiallergic drugs. Ann Allergy Asthma Immunol. 1986;56:464469

Thompson BT. Glucocorticoids and acute lung injury. Crit Care Med. 2003;31:S253-S257.

Verdier F, Chazal I, Descotes J. Anaphylaxis models in the guinea-pig. Toxicology. 1994;93:55-61.

Wershil BK, Furuta GT, Lavigne JA, Choudhury AR, Wang ZS, Galli SJ. Dexamethasone or cyclosporin A suppress mast cellleukocyte cytokine cascades. Multiple mechanisms of inhibition of IgE- and mast cell-dependent cutaneous inflammation in the mouse. J Immunol. 1995;154:1391-1398.

Wershil BK, Mekori YA, Murakami T, Galli SJ. 125I-fibrin 
deposition in IgE-dependent immediate hypersensitivity reactions in mouse skin. Demonstration of the role of mast cells using genetically mast cell-deficient mice locally reconstituted with cultured mast cells. J Immunol. 1987;139:2605-2614. 